\title{
Grid Connected Inverter for Current Control by Using Anti- Islanding Technique
}

\author{
B V Rajanna ${ }^{1}$, Dr K S Srikanth ${ }^{2}$ \\ ${ }^{1}$ Department of Electrical and Electronics Engineering, K L E F, Vaddeswaram, Guntur, A.P., India \\ ${ }^{2}$ Department of Electrical and Electronics Engineering, K L E F, Vaddeswaram, Guntur, A.P., India
}

\begin{tabular}{l}
\hline Article Info \\
\hline Article history: \\
Received Dec 21, 2017 \\
Revised Jan 22, 2018 \\
Accepted Feb 7, 2018 \\
\hline
\end{tabular}

\section{Keyword:}

Islanding, inverter

Reactive power

Critical load

Micro-grid

Indirect current control

\begin{abstract}
The inverter with critical loads should be able to provide critical loads with a stable and seamless voltage during control mode change as well as clearing time. The indirect current control has been proposed for providing stable voltage with critical load during clearing time and seamless control mode transfer of inverters. However, the islanding detection is difficult since with the indirect current control the magnitude and frequency of voltage do not change when the islanding occurs. The conventional anti-islanding method based on the magnitude and frequency of voltage variation cannot apply to the indirect current control. This paper proposes an islanding detection method for the indirect current control. The proposed islanding detection method can detect the islanding using reactive power perturbation and observation when the frequency and magnitude of voltage don't vary during clearing time. In order to verify the proposed anti-islanding method, the experimental results of a $600 \mathrm{~W}$ three-phase inverter are provided.
\end{abstract}

Copyright $(2) 2018$ Institute of Advanced Engineering and Science. All rights reserved.

\section{Corresponding Author:}

B V Rajanna

Department of Electrical and Electronics Engineering,

Koneru Lakshmaiah Education Foundation( K L E F),

Green fields, Vaddeswaram, Guntur, Andhra Pradesh, India.

Email: rajannabv2012@gmail.com

\section{INTRODUCTION}

The micro-grid is considered as a possible solution to the reliability limitation of the traditional power system [1].The micro-gird consists of energy storage systems (ESS) and distributed generation (DG) systems such as photovoltaic (PV), wind power and a cluster of critical load. Figure 1 shows the circuit diagram of the grid-connected inverter for ESS with a critical load. When an islanding occurs the inverter for ESS should detect the islanding within 2 seconds and disconnect the inverter from the grid according to IEEE 1547 and 929 standards [2-5]. During the clearing time the magnitude and frequency of voltage across the critical load may vary as shown in Figure 2, since the voltage is determined by the amount of the injected power and load condition. Further, a large transient may occur on the critical load at actual turn off of the switch since the inverter based on the conventional control method changes from current control to voltage control modes. Regarding this concern, an indirect current control was proposed in [6-10] for seamless transfer during the clearing time as well as at turn-off of the switch. However, since the indirect current control does not make the magnitude and frequency of voltage across the load vary when an islanding occurs, the conventional anti-islanding method such as the reactive power variation (RPV), the magnitude and frequency positive feedback and the active frequency drift (AFD) based on the magnitude and frequency of voltage variation cannot be applied to the indirect current control [11-15]. The harmonic injection antiislanding method can detect the islanding, but it may cause a severe distortion in current and voltage of the critical load [16-20]. 


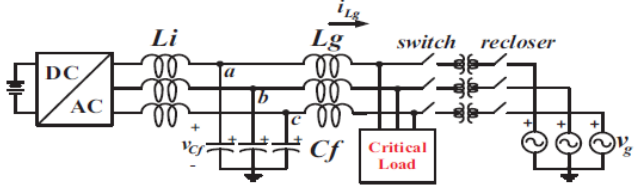

Figure 1. Grid connected inverter with critical load

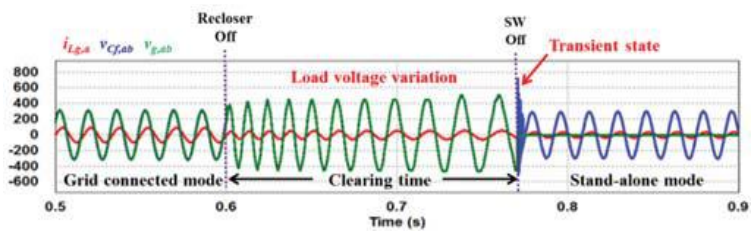

Figure 2. Simulation of mode transfer with Conventional control

In this paper, an islanding detection method for the indirect current control is proposed. The proposed islanding detection method can detect the islanding using reactive power perturbation and observation in the inverter being operated based on indirect current control, which does not cause a change in magnitude and frequency of critical load voltage. The inverter detects reactive power mismatch between inverter reactive power $Q$ and reactive power reference $Q^{*}$, leading to detection of islanding condition. Therefore in the inverter based on indirect current control the proposed antiislanding method can detect islanding. Finally the experimental result from a $600 \mathrm{~W}$ three-phase inverter verifies that the proposed antiislanding method can detect the islanding without NDZ.

\section{PROPOSED ANTI-ISLANDING}

\subsection{Conventional RPV anti-islanding method}

According to IEEE 1547 and 929 standards, an islanding test scheme for verification of the antiislanding method is shown in Figure 3. The islanding test scheme consists of a grid connected inverter, a RLC load, a switch, a recloser and the grid. Quality factor of the RLC load is 2.5, and resonant frequency fres is set to be the same as grid frequency. Then, values of the RLC load is determined by (1) and (2).

$$
\begin{aligned}
& Q_{f}=R \sqrt{\frac{C}{L}} \\
& f_{r e s}=\frac{1}{2 \pi \sqrt{L C}}
\end{aligned}
$$

Active and reactive powers of the RLC loads can be expressed, respectively, as follows:

$$
\begin{gathered}
P_{\text {Load }}=3 \frac{V_{P C C}^{2}}{R} \\
Q_{\text {Load }}=3\left(\frac{V_{P C C}^{2}}{2 \pi f L}-2 \pi f C . V_{P C C}^{2}\right)
\end{gathered}
$$

where $V_{P C C}$ and f represent voltage and frequency of PCC, respectively. By combining (1), (2), (3) and (4), $Q_{\text {Load }}$ can be rewritten as

$Q_{\text {Load }}=P_{\text {Load }} Q_{f}\left(\frac{f_{\text {res }}}{f}-\frac{f}{f_{\text {res }}}\right)$

Equation (5) shows that the load reactive power is zero when frequency equal to the resonance frequency. In Fig. 3(a) showing the grid-connected mode, the load reactive power $Q_{\text {Load }}$ is the sum of inverter reactive power $Q$ and grid reactive power $\Delta Q$ :

$Q_{\text {Load }}=Q+\Delta Q$ 


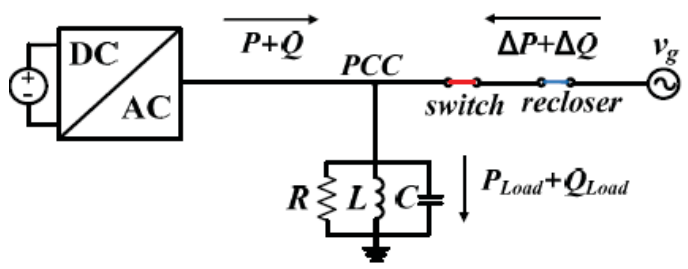

(a)

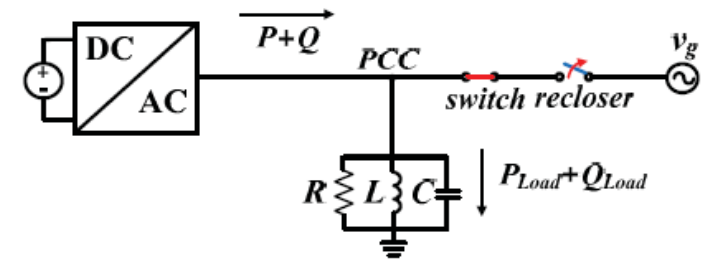

(b)

Figure 3. Islanding test scheme (a) Grid connected mode, (b) Islanding mode

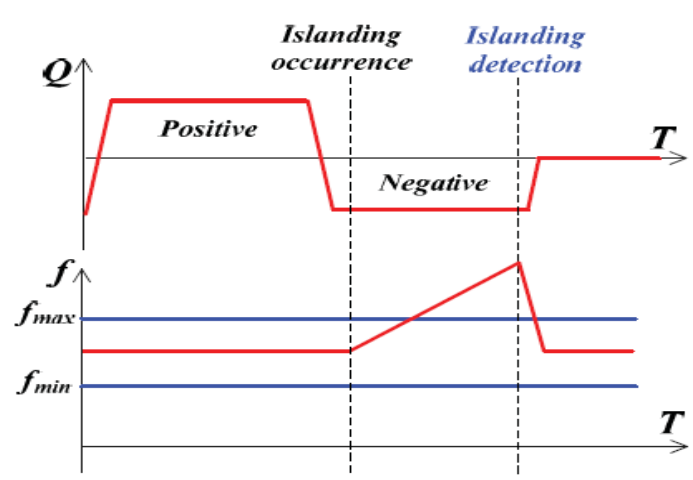

Figure 4. Conventional RPV anti-islanding method

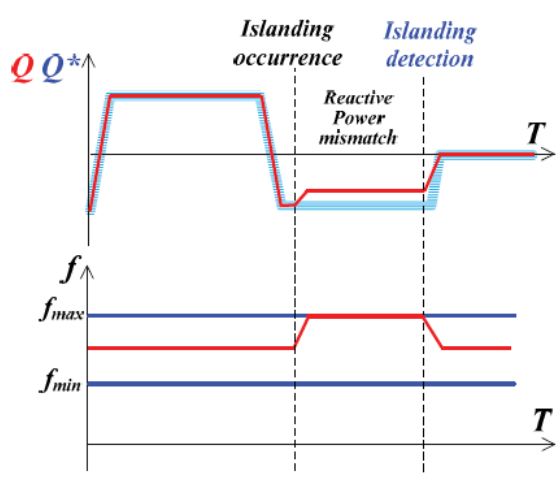

Figure 5. Reactive Power P\&O anti-islanding method

When the grid is connected the load reactive power is zero, and the inverter supplies reactive power to the grid. In the conventional Reactive Power Variation (RPV) method the inverter changes reactive power periodically, as shown in Figure 4. Then, when the islanding occurs the RPV method forces the frequency of $V_{P C C}$ to exceed the frequency thresholds, leading to detection of islanding condition. In Figure 3(b) showing the islanding mode, the inverter reactive power is equal to the load reactive power:

$Q_{\text {Load }}=Q$

Because the load reactive power $Q_{L o a d}$ is determined by frequency of $V_{P C C}$, the inverter changes frequency of $V_{P C C}$ for reactive power output. Therefore, the frequency of $V_{P C C}$ exceeds the frequency thresholds and the islanding is detected.

\subsection{Proposed Reactive Power P\&O Anti-islanding method}

The conventional RPV method detects variation in the frequency of VPCC. However, with the indirect current control the frequency of $V P C C$ does not change when the islanding occurs. Therefore, the conventional RPV method cannot be applied to the indirect current control. The proposed antiislanding method use reactive power variation, but an islanding detection indicator is not frequency but reactive power. In Fig. 5, the proposed islanding method detects reactive power mismatch between inverter reactive power $Q$ and reactive power reference $Q^{*}$. If the frequency of $V P C C$ is limited by allowable maximum frequency $f_{\max }$ and maximum frequency $f_{\min }$ according to IEEE 1547 and 929 standards, the inverter reactive power $Q$ is also limited when the islanding occurs. When the islanding occurs, the inverter reactive power range is defined as

$P_{\text {Load }} Q_{f}\left(\frac{f_{\text {res }}}{f_{\text {min }}}-\frac{f_{\text {min }}}{f_{\text {res }}}\right) \leq Q\left(=Q_{\text {Load }}\right) \leq P_{\text {Load }} Q_{f}\left(\frac{f_{\text {res }}}{f_{\text {max }}}-\frac{f_{\text {max }}}{f_{\text {res }}}\right)$

If reactive power reference $Q^{*}$ exceeds reactive power range of equation (8), the inverter cannot generate the reactive power reference when the islanding occurs, resulting in the islanding detection. Therefore, the proposed anti-islanding method based on the reactive power can be applied to the indirect current control. 


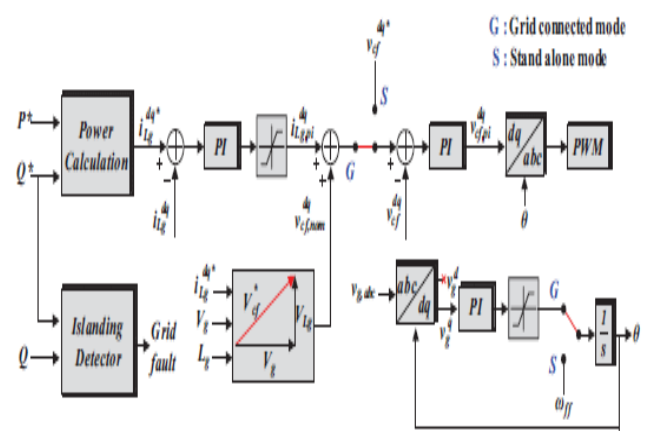

Figure 6. Proposed control algorithm

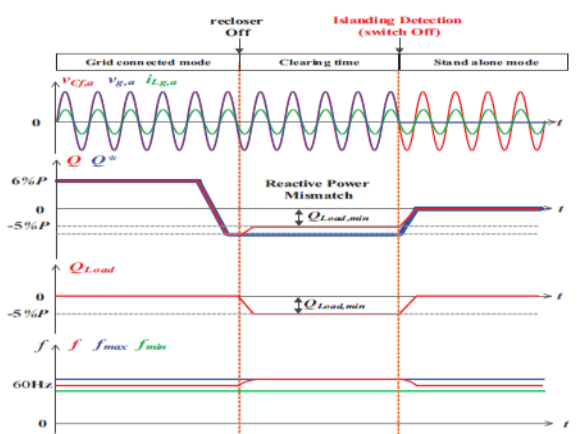

Figure 7. Key waveform of the proposed P\&O antiislanding method

Figure 6 illustrates the control block diagram of the proposed anti-islanding method for the indirect current control. The proposed anti-islanding method consists of a reactive power perturbation for changing reactive power reference $Q^{*}$ periodically and a reactive power observation for measuring reactive power $Q$. The islanding detector detects the mismatch between inverter reactive power $Q$ and reactive power reference $Q^{*}$.The indirect current control consists of an outer current control loop for regulating current and an inner voltage control loop for controlling capacitor voltage. Both current control and voltage control loops are used for the grid connected mode, and a single voltage loop is used for the standalone mode. Current command $i_{L g}$ $d q^{*}$ can be obtained by power calculation, respectively:

$i_{L g}^{q^{*}}=\frac{\frac{2}{3}\left(P^{*} V_{g}^{q}+Q^{*} V_{g}^{d}\right)}{\left(V_{g}^{d}\right)^{2}+\left(V_{g}^{q}\right)^{2}}$

$i_{L g}^{d^{*}}=\frac{\frac{2}{3}\left(P^{*} V_{g}^{d}-Q^{*} V_{g}^{q}\right)}{\left(V_{g}^{d}\right)^{2}+\left(V_{g}^{q}\right)^{2}}$

Capacitor voltage reference $V_{C f^{*}}$ can be obtained by adding nominal value $V_{C f, n o m}{ }^{d q}$ to output $i_{L g, P I} d q$ of the current controller. The outputs of the current controller and PLL are restricted by the limiters. Figure 7 shows key waveforms of the reactive power $\mathrm{P} \& \mathrm{O}$ anti-islanding method based on the indirect current control. In the grid connected mode inverter reactive power $Q$ is regulated to follow the reactive power reference $Q^{*}$, and load reactive power $Q_{\text {Load }}$ is zero. When the islanding occurs, the magnitude and frequency of the capacitor voltage do not change limiters, and inverter reactive power $Q$ isn't regulated, resulting in the islanding detection. It is seen that the transient voltage across the load is negligible at actual turn-off of the switch since the voltage control is well maintained.

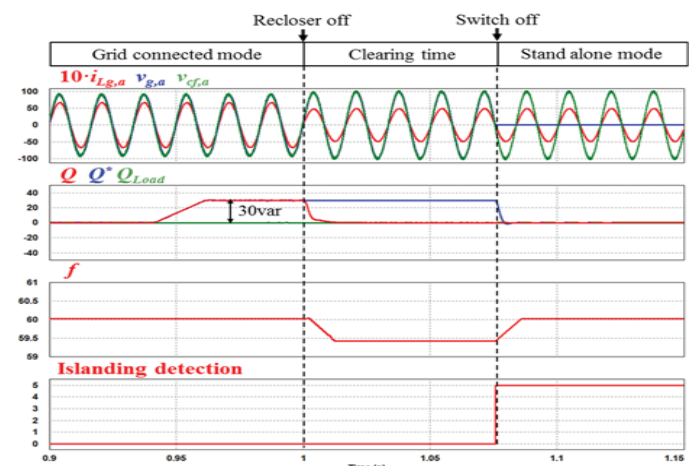

(a)

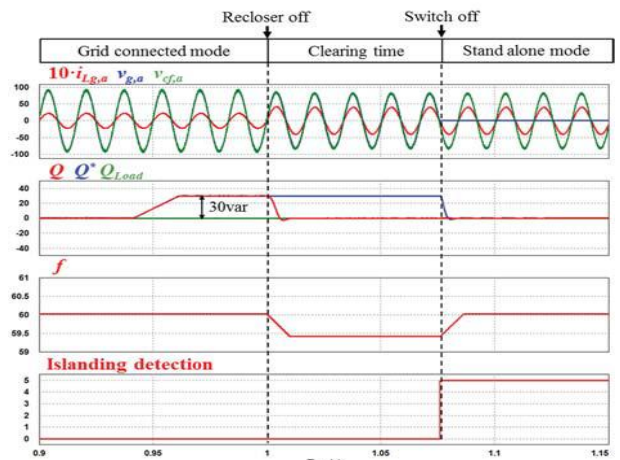

(b)

Figure 8. Simulation results of the proposed islanding detection method under resistive load condition. When the grid is connected, (a) $\mathrm{P}=1 \mathrm{~kW}, P_{\text {Load }}=500 \mathrm{~W}, \Delta P=-500 \mathrm{~W}$ (b) $P=250 \mathrm{~W}, P_{\text {Load }}=500 \mathrm{~W}, \Delta P=250 \mathrm{~W}$ 


\section{SIMULATION RESULT}

In order to validate the proposed anti-islanding method, simulations have been done under the condition of resistive load, reactive load and RLC load with the quality factor of 2.5 , respectively. The system specification used in the simulation is as follows: $P_{o}=500 \mathrm{~W}, V_{D C}=225 \mathrm{~V}, V_{\text {grid }}=64 \mathrm{~V}, L_{i}=1.68 \mathrm{mH}$, $L_{g}=3 \mathrm{mH}$ and $C_{f}=3 \_$F. Figure $8(\mathrm{a})$ and (b) show the islanding detection results under the resistive load condition. When the grid is connected the inverter reactive power $Q$ changes periodically, and the load reactive power $Q_{\text {load }}$ is zero. When the islanding occurs, the inverter reactive power $Q$ becomes zero since the inverter reactive power $Q$ is equal to the load reactive power $Q_{\text {load, }}$ and then the islanding is detected due to reactive power mismatch between the inverter reactive power $Q$ and the reactive power reference $Q^{*}$. Figure 9 and 10 show the islanding detection results under the reactive load condition. When the islanding occurs, the inverter exceeds thresholds output frequency $f$ to regulate the inverter reactive power $Q$, but cannot regulate reactive power $Q$ since $f$ is limited by frequency limiter, resulting in the islanding detection.

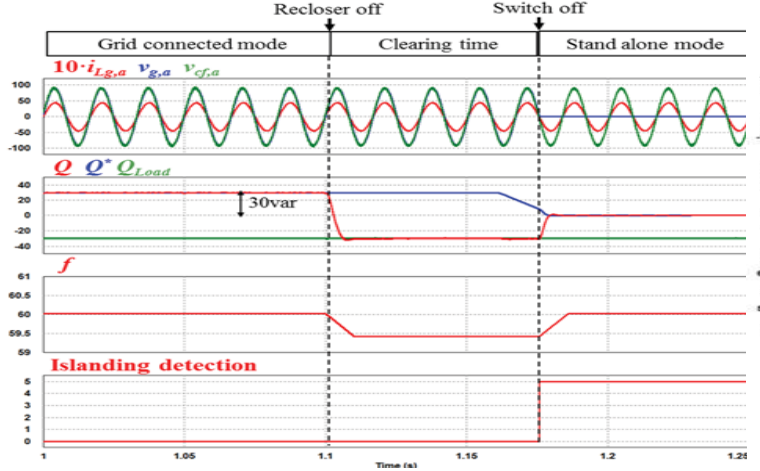

(a)

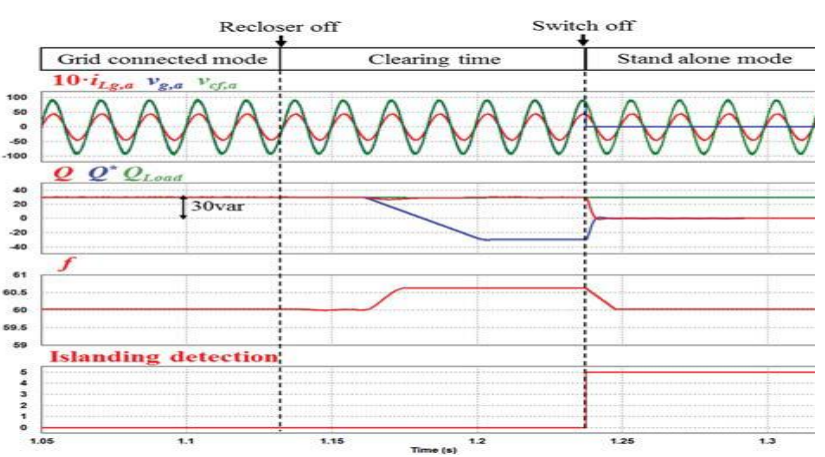

(b)

Figure 9. Simulation results of the proposed islanding detection method under reactive load condition. When the grid is connected, (a) $P=P_{\text {Load }}=500 \mathrm{~W}, \Delta P=0 \mathrm{~kW}, Q_{\text {Load }}=-30 \mathrm{var}$ (b) ) $P=P_{\text {Load }}=500 \mathrm{~W}, \Delta P=0 \mathrm{~kW}$, $Q_{\text {Load }}=30 \mathrm{var}$

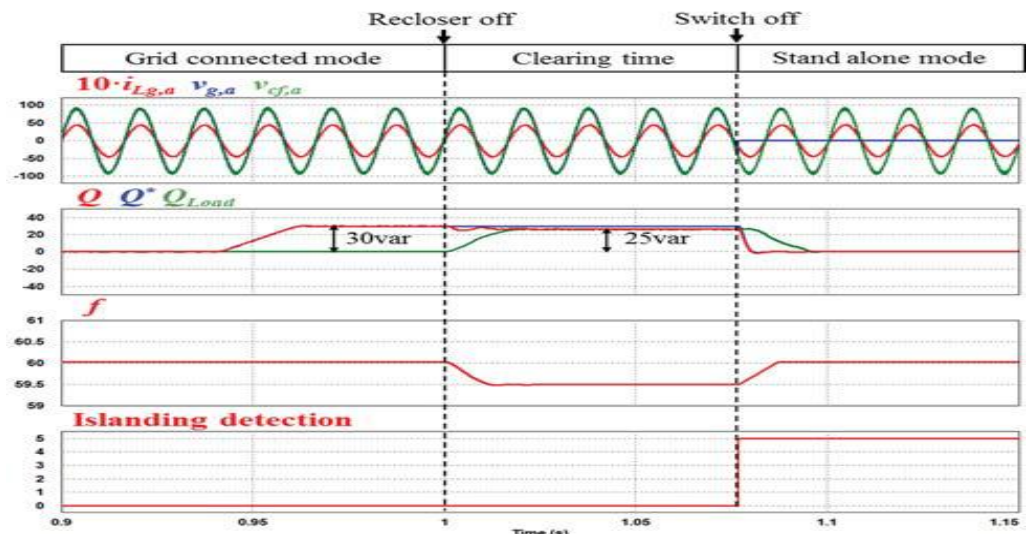

Figure 10. Simulation results of the proposed islanding detection method under RLC load(quality factor=2.5) condition 


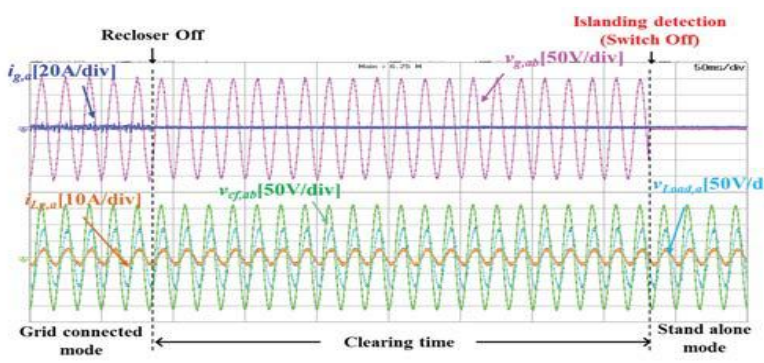

(a)

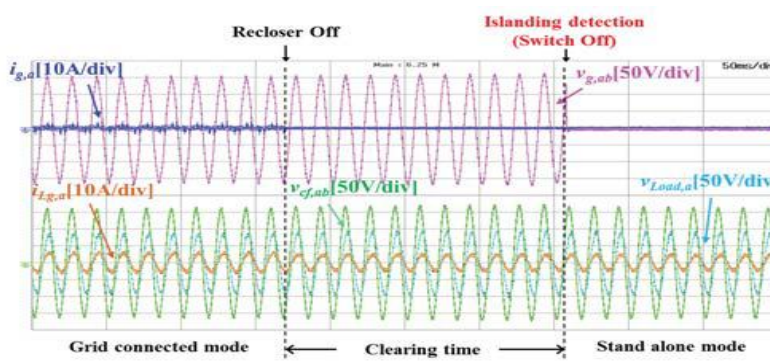

(b)

Figure 11. Experimental results of the proposed islanding detection method showing the mode transfer from stand-alone mode to grid-connected mode when islanding occurs. When the grid is connected, (a) $P=P_{\text {Load }}$,

$$
\Delta P=0 \mathrm{~W}, \Delta Q=0 \mathrm{~W} \text { (b) } P=P=P_{\text {Load }}+300 \mathrm{~W}, \Delta P=-300 \mathrm{~W}, \Delta Q=0 \mathrm{~W}
$$

\section{EXPERIMENT RESULT}

A $600 \mathrm{~W}$ three-phase inverter is built and tested to verify the proposed anti-islanding method, and the experimental results are provided. The system specification used in the experiment is as follows: $P_{o}=$ $600 \mathrm{~W}, V_{D C}=225 \mathrm{~V}, V_{\text {grid }}=64 \mathrm{~V}, L_{i}=1.68 \mathrm{mH}, L_{g}=3 \mathrm{mH}$ and $\mathrm{C}_{f}=3 \_\mathrm{F}, \mathrm{RLC}$ Load (quality factor $=2.5$ ), Figs. 11(a) and (b) show the islanding detection within 2 seconds and the seamless mode transfer from gridconnected mode to stand-alone mode when the islanding occurs.

\section{CONCLUSION}

The conventional anti-islanding method cannot be applied to the indirect current control since the magnitude and frequency of voltage do not change even after the islanding occurs. An issue of detecting the islanding arose for the indirect current control method. In this paper, a new islanding detection method that can be applied to the indirect current control is proposed. The proposed islanding detection method can detect the islanding using reactive power perturbation and observation in the inverter being operated based on indirect current control, which does not cause a change in magnitude and frequency of critical load voltage not only during clearing time but at the moment of mode change. In order to verify the proposed islanding detection method, the experimental results of a $600 \mathrm{~W}$ three-phase inverter with RLC load (qfactor=2.5) are provided. The experimental results show that the proposed islanding detection method is effective in detect islanding within 2 seconds according to IEEE 1547 and 929 standards, while providing stable and seamless voltage for critical load.

\section{ACKNOWLEDGEMENTS}

I express my thanks to the support given by management in completing my project. I also express my sincere gratitude \& deep sense of respect to Dr. K S Srikanth for making us available all the required assistance \& for his support \& inspiration to carry out this project in the Institute. I would like to thank Dr. K S Srikanth, professor who has been an inspiring guide and committed faculty who gave relief moral support in every situation of engineering career. The encouragement and support by him, especially in carrying out this project motivated me to complete this project. I am thankful to the teaching and non-teaching staff of EEE department for their direct as well as indirect help in my project. I am elated to avail my selves to this opportunity to express my deep sense of gratitude to my parents.

\section{REFERENCES}

[1] IEEE Recommended Practice for Utility Interface of Photovoltaic (PV) Systems, IEEE Standard 929-2000, Apr.2000.

[2] IEEE Standard for Interconnecting Distributed Resources with Electric Power Systems, IEEE Standard 1547-2003, Jul. 2003.

[3] J. B. Jeong, H. J. Kim, “Active anti-islanding method for PV system using reactive power control”, Electronics Letters 17th, 2006, Vol. 42, No. 17.

[4] W. Xu, G. Zhang, C. Li, W. Wang, G. Wang and J. Kliber, "A Power Line Signaling Based Technique for AntiIslanding Protection of Distributed Generators-Part I: Scheme and Analysis," in IEEE Transactions on Power Delivery, vol. 22, no.3, pp.1758-1766, July2007.doi: 10.1109/TPWRD.2007.899618. 
[5] H. Kim, T. Yu, and S. Choi, "Indirect current control algorithm for utility interactive inverters in distributed generation systems," IEEE Trans. Power Electron., vol. 23, no. 3, pp. 1342-1347, May 2008.

[6] P. Du, Z. Ye, E. Aponte, J. Nelson, and L. Fan, "Positive-feedbackbased active anti-islanding schemes for inverterbased distributed generators: Basic principle, design guideline, and performance analysis," IEEE Trans. Power Electron., vol. 25, no. 12, pp. 2941-294, Dec. 2010.

[7] J. Benjanarasut and B. Neammanee, "The d-, q- axis control technique of single phase grid connected converter for wind turbines with MPPT and anti-islanding protection," The 8th Electrical Engineering/ Electronics, Computer, Telecommunications and Information Technology (ECTI) Association of Thailand - Conference 2011, Khon Kaen, 2011, pp.649-652.doi: 10.1109/ECTICON.2011.5947923.

[8] A. Yafaoui, B. Wu, and S. Kouro, "Improved active frequency drift antiislanding detection method for grid connected photovoltaic systems," IEEE Trans. Power Electron., vol. 27, no. 5, pp. 2367-2375, May 2012.

[9] Y. Zhu, D. H. Xu, N. He, J. Ma, J. Zhang, Y. F. Zhang, G. Q. Shen, and C. S. Hu, "A novel RPV (reactive-powervariation) antiislanding method based on adaptive reactive power perturbation," IEEE Trans. Power Electron., vol. 28, no. 11, pp. 4998-5012, Nov. 2013.

[10] J. Zhang, D. Xu, G. Shen, Y. Zhu, N. He, and J. Ma, "An improved islanding detection method for a gridconnected inverter with intermittent bilateral reactive power variation," IEEE Trans. Power Electron., vol. 28 , no. 1, pp. 268-278, Jan. 2013.

[11] D. E. Olivares et al., "Trends in microgrid control," IEEE Trans. Smart Grid, vol. 5, no. 4, pp. 1905-1919, Jul. 2014.

[12] S. Yoon, H. Oh, S. Choi, "Controller Design and Implementation of Indirect Current Control Based UtilityInteractive Inverter System,” IEEE Trans. Power Electron. vol. 28, no. 1, Jan. 2013.

[13] S. Kar and S. R. Samantaray, "Multiple features based anti-islanding protection relay for distributed generations," 2014 International Conference on Smart Electric Grid (ISEG), Guntur, 2014, pp. 1-6. doi: 10.1109/ISEG.2014.7005602.

[14] B. Guha, R. J. Haddad and Y. Kalaani, "Anti-islanding techniques for Inverter-based Distributed Generation systems -A survey," SoutheastCon2015, FortLauderdale, FL,2015,pp.1-9.doi: 10.1109/SECON.2015.7133045.

[15] T. Kandil, "Performance evaluation of anti-islanding protection technique for Micro Grids," 2015 International Symposium on Smart Electric Distribution Systems and Technologies (EDST), Vienna, 2015, pp. 447-451. doi: 10.1109/SEDST.2015.7315250.

[16] A. Datta, D. Saha, A. Ray and P. Das, "Evaluation of anti-islanding techniques for renewable energy powered distributed generators using analytic network process," in IET Renewable Power Generation, vol. 10, no. 9, pp. 1245-1254, 102016.doi: 10.1049/iet-rpg.2015.0461.

[17] S. Patra, S. Agrawal, S. R. Mohanty, V. Agarwal and M. Basu, "ESPRIT based robust anti-islanding algorithm for grid-tied inverter," 2016 IEEE Students' Technology Symposium (TechSym), Kharagpur, 2016, pp. 90-95. doi: 10.1109/TechSym.2016.787266.

[18] C. R. Aguiar, G. Fuzato, R. F. Bastos, A. F. Q. Gonçalves and R. Q. Machado, "Hybrid fuzzy anti-islanding for grid-connected and islanding operation in distributed generation systems," in IET Power Electronics, vol. 9, no. 3, pp. 512-518, 392016.doi: 10.1049/iet-pel.2014.0717

[19] D. Voglitsis, N. Papanikolaou and A. C. Kyritsis, "Incorporation of Harmonic Injection in an Interleaved Flyback Inverter for the Implementation of an Active Anti-Islanding Technique," in IEEE Transactions on Power Electronics, vol.32, no.11, pp.8526-8543, Nov.2017. doi: 10.1109/TPEL.2016.2646419.

[20] M. Khodaparastan, H. Vahedi, F. Khazaeli and H. Oraee, "A Novel Hybrid Islanding Detection Method for Inverter- Based DGs Using SFS and ROCOF," in IEEE Transactions on Power Delivery, vol. 32, no. 5, pp. 21622170, Oct. 2017.doi: 10.1109/TPWRD.2015.2406577. 